\title{
Identification, characterization and molecular epidemiology of Escherichia coli isolated from lamb and goat kids with diarrhoea
}

\author{
Suheyla Turkyilmaz ${ }^{1}$, Seza Eskiizmirliler ${ }^{2}$, Serra Tunaligil², Bulent Bozdogan ${ }^{3}$ \\ ${ }^{1}$ Adnan Menderes University, Faculty of Veterinary Medicine, Department of Microbiology, Aydin, Turkey \\ ${ }^{2}$ Bornova Veterinary Control Institute, Izmir, Turkey \\ ${ }^{3}$ Adnan Menderes University, Medical Faculty, Department of Medical Microbiology, Aydin, Turkey
}

Received April 13, 2013

Accepted September 26, 2013

\begin{abstract}
Neonatal diarrhoea is a serious health problem on commercial farms. Enterovirulent Escherichia coli is a significant aetiological agent of neonatal diarrhoea. In this work, identification and classification of $E$. coli isolates obtained from lambs and goat kids with diarrhoea were studied along with antibiotic resistance and clonal relationships of enterovirulent strains. A total of 107 E. coli strains isolated from animals on 43 farms were investigated. Specific virulence genes were determined by multiplex and uniplex polymerase chain reaction. Testing of antibiotic susceptibility was carried out by the Vitek II compact system. The relationship of $E$. coli isolates was determined by enterobacterial repetitive intergenic consensus polymerase chain reaction. A total of $39(36.4 \%)$ enterovirulent $E$. coli strains were identified and of this $19(48.7 \%)$ were shiga toxigenic, $12(30.8 \%)$ enterotoxigenic and 8 (20.5\%) enteropathogenic. Three isolates $(7.7 \%)$ were found to be positive for extended spectrum beta lactamase; $10(25.6 \%)$ isolates showed multi-drug resistance to antimicrobials. A total of 28 types were detected by enterobacterial repetitive intergenic consensus polymerase chain reaction. Twenty strains had distinct types while 5 types were common for 2 strains and 3 types were common for 3 strains. This is the first current determination of types, clonality and antibiotic resistance of enterovirulent $E$. coli isolated from small ruminants with diarrhoea. The results of this study showed that the rates of shiga toxigenic, enterotoxigenic and enteropathogenic isolates of $E$. coli are high in the western part of Turkey. Although these isolates were not clonal, presence of multidrug resistant isolates may cause public health problems.
\end{abstract}

\section{E. coli, virulence genes, antimicrobial susceptibility, ERIC PCR}

Among bacterial pathogens worldwide, enterovirulent Escherichia coli ranks among the most common causative agents of bacterial diarrhoea in several animal species as well as in humans. The strains of E. coli can be divided into five groups or pathotypes. Types of diarrhoeagenic E. coli include enterotoxigenic (ETEC), enteropathogenic (EPEC), enteroinvasive (EIEC) and enteroaggregative (EAEC) enterohaemorrhagic E. coli (EHEC) (Nataro and Kaper 1998). The Shiga toxin-producing group of E. coli strains is capable of producing toxins very similar to the one produced by Shigella dysenteriae type 1 . Therefore, these bacteria are often called Shiga toxin-producing E. coli (STEC). Active Shiga toxins may be detected using Vero cell toxicity test (Beutin et al. 2007). This is why these bacteria are also called verotoxin or verocytotoxin-producing $E$. coli (VTEC). The Shiga toxins produced by E. coli may cause anything from uncomplicated diarrhoea to haemorrhagic colitis, which can progress into haemolytic uremic syndrome (HUS). Thus, the bacterium is often called also EHEC. Animals are the main reservoir for STEC (Nataro and Kaper 1998).

Strains of pathogenic E. coli, which have acquired virulence genes, have the ability to cause diarrhoeal disease. The shigatoxigenic (STEC or VTEC) strains produce shiga toxins 1 and/or 2 (stx 1 , stx 2$)$ while EHEC produce stx 1 and/or st $x 2$ and intimin (eaeA). The ETEC strains produce heat labile (LT) and/or heat stable (ST) enterotoxins, while EPEC strains may have the EPEC adherence plasmid (EAF) that carries the bundle forming pilus $(b f p)$. The EIEC strains have the ability to invade the colon epithelial cells due to presence

Address for correspondence:

Dr. Suheyla Turkyilmaz

Department of Microbiology, Faculty of Veterinary Medicine

Adnan Menderes University, Aydin, 09010, Turkey
Phone: +90256247 07 00/292
Fax:+9025624707 00
E-mail: sturkyilmaz@adu.edu.tr
http://actavet.vfu.cz/ 
of a plasmid that carry the ial gene. The EAEC strains are characterized by presence of aggregative adherence factors (AAFs). The expression of these factors is regulated by transcription activation factor encoded by the aaflI gene. Molecular methods remain the most suitable techniques for differentiating diarrhoeagenic strains of $E$. coli from nonpathogenic ones (Nataro and Kaper 1998).

The aim of this work was to classify pathogenic $E$. coli strains, their antimicrobial resistance profiles and clonal relations of these strains isolated from lambs and goat kids with diarrhoea.

\section{Materials and Methods}

Sample collection on farms

A total of $107 \mathrm{E}$. coli isolates obtained from 79 lambs and 28 goat kids on 43 farms were investigated. Samples were mainly collected between 2007 and 2009 from sheep and goat farms located in Izmir located in the western part of Turkey. Data on sex and breed of animals were not available. Both species were mostly reared under semi extensive husbandry for dairy and/or meat production. Two or three samples were taken from every farm. Animals receiving antimicrobial treatment and animals older than 45 days were excluded from the study. Swabs were taken from the rectum of live animals and placed immediately in $1 \mathrm{ml}$ of $0.1 \mathrm{M}$ sterile phosphate buffered saline (PBS) and diluted 1:10 in PBS.

Isolation and identification of E. coli

Faeces samples were inoculated onto McConkey agar. Agar plates were incubated at $37{ }^{\circ} \mathrm{C}$ and bacterial growth was evaluated after 24 and $48 \mathrm{~h}$. Gram negative microorganisms were selected using MacConkey agar and identified with biochemical tests (Quinn et al. 1994). The confirmation of the E. coli identifications was done with the Vitek II system (Biomerieux, France).

Testing of antimicrobial susceptibility

The activities of 15 antibiotics (ampicillin, amoxicillin-clavulanic acid, piperacillin, gentamicin, tobramicin, amikacin, imipenem, tetracycyline, cefpodoxime, ceftiofur, enrofloxacin, marbofloxacine, chloramphenicol, trimethoprim-sulfamethoxazole and nitrofurantoin) and determination of the presence of extended spectrum beta lactamase (ESBL) were carried out with the Vitek II compact system using the Vitek II AST-GN38 cards as described previously (Ling et al. 2001). The E. coli reference strain (ATCC 25922) was used as quality control. Interpretation of results was performed according to National Committee for Clinical Laboratory Standards (CLSI 2007).

Virulence genes and clonality of E. coli strains

Genomic DNA from individual pure cultures of $E$. coli isolates was extracted by InstaGene matrix (Bio-Rad Laboratories, Canada) according to the manufacturer's instructions. Genes of virulence $s t x 1$ and/or stx2, st and/ or $l t$, eae and/or bfp, ial and $a a f I I$ specific for strains EHEC, ETEC, EPEC, EIAC and EAEC, respectively, were used in this study. Multiplex PCR was performed for the detection of stx 1 , stx 2 and eae genes; uniplex PCR was used for detection of $l t, s t, b f p$, ial and aafII genes. PCR conditions are given in Table 1 . The primers used in

Table 1. PCR conditions for the detection of virulence genes and clonality of pathogen $E$. coli strains.

\begin{tabular}{|c|c|c|c|c|c|c|c|c|c|}
\hline & \multicolumn{3}{|c|}{$\mathrm{uPCR}^{1}$} & \multicolumn{3}{|c|}{$\mathrm{mPCR}^{2}$} & \multicolumn{3}{|c|}{ ERIC PCR } \\
\hline & $\begin{array}{c}\text { Temperature } \\
\left({ }^{\circ} \mathrm{C}\right)\end{array}$ & $\begin{array}{c}\text { Duration } \\
\text { (min) }\end{array}$ & Cycles & $\begin{array}{c}\text { Temperature } \\
\left({ }^{\circ} \mathrm{C}\right)\end{array}$ & $\begin{array}{l}\text { Duration } \\
\text { (min) }\end{array}$ & Cycles & $\begin{array}{c}\text { Temperature } \\
\left({ }^{\circ} \mathrm{C}\right)\end{array}$ & $\begin{array}{l}\text { Duration } \\
\text { (min) }\end{array}$ & Cycles \\
\hline $\begin{array}{l}\text { Initial } \\
\text { denaturation }\end{array}$ & 94 & 5 & 1 & 94 & 5 & 1 & 94 & 5 & 1 \\
\hline Denaturation & 94 & 1 & 35 & 94 & 1 & 35 & 94 & 1 & 35 \\
\hline Annealing & 50 & 1 & 35 & 51 & 1 & 35 & 43 & 1 & 35 \\
\hline Extension & 72 & 1 & 35 & 72 & 2 & 35 & 72 & 3 & 35 \\
\hline Elongation & 72 & 10 & 1 & 72 & 10 & 1 & 72 & 10 & 3 \\
\hline Cooling & 4 & infinite & & 4 & infinite & & 4 & infinite & \\
\hline
\end{tabular}

${ }^{1}$ Presence of genes $b f p$, ial, and aafII were tested by uPCR, ${ }^{2}$ Presence of genes $s t x 1$, stx2, eae and $l t$, st were tested by mCR ERIC - Enterobacterial Repetitive Intergenic Consensus 
PCR for $s t x 1, s t x 2, l t, s t$, ial and eae genes were those as reported by Lopez-Saucedo et al. (2003), for $b f p \mathrm{~A}$ (Stacy-Phipps et al. 1995), for aafII (Vidal et al. 2005) and for enterobacterial repetitive intergenic consensus (ERIC) (Versalovic et al. 1991). Reference strains of E. coli ATCC 35150 (EHEC; stx1, stx2, eae positive), ATCC 35401 (ETEC; lt, st positive), and ATCC 43893 (EIEC; ial positive) were used as positive control strains and ATCC 25922 was used as negative control strain. The strains EAEC (aaflI positive) and standard EPEC ( $b f p \mathrm{~A}$ positive) could not be obtained due to the restrictions on export. Uniplex PCR was used to detect the clonality by enterobacterial repetitive intergenic consensus (ERIC) PCR. For ERIC PCR, genetic relationships were calculated and a dendogram was designed by the Bio-1D++ program (Vilber Lourmat, Germany), relying on the existence of bands. In this study, a $b f p \mathrm{~A}$ positive PCR amplicon was sequenced by a private company (Macrogen, Korea). The amplification products were analysed by electrophoresis on 1.5\% agarose gel at $100 \mathrm{~V}$ for $30 \mathrm{~min}$ in Tris-acetate-EDTA buffer and revealed in ethidium bromide $(20 \mu \mathrm{g} / \mathrm{ml})$.

\section{Results}

Among 107 E. coli strains isolated, 39 (36.4\%) were found to carry at least one of the virulence genes tested by PCR (Table 2, Plate I, Fig. 1). Isolates of E. coli were mostly resistant to tetracycyline (40\%). Three isolates were found to be ESBL positive. A total of 22 isolates $(56.4 \%)$ were found to be susceptible to all antimicrobials, whereas 10 $(25.6 \%)$ of them showed multi antimicrobial resistance (resistance against three or more antimicrobials). Seven, 3, 2, 3 and 2 isolates were resistant to 1, 3, 4, 5 and 11 antimicrobials, respectively.

Table 2. Classification of enterovirulent $E$. coli strains isolated from lamb and goat kids with diarrhoea by multiplex and uniplex PCR.

\begin{tabular}{lccc}
\hline Category & Virulence genes & $\begin{array}{c}\text { Number of } \\
\text { virulence genes }(\%)\end{array}$ & $\begin{array}{c}\text { Number of } \\
\text { enterovirulent isolates }(\%)\end{array}$ \\
\hline STEC & $s t x 1$ & $1(2.6)$ & $15(38.4 \%)$ \\
EHEC & $s t x 2$ & $13(33.2)$ & $4(10.2 \%)$ \\
ETEC & $s t x 1+s t x 2$ & $1(2.8)$ & $12(30.8)$ \\
EPEC & $s t x 2+e a e \mathrm{~A}$ & $4(10.2)$ & $8(20.6)$ \\
EIEC & $s t$ & $1(2.6)$ & 0 \\
EAEC & eaeA & $11(28.2)$ & 0 \\
Total $(\%)$ & bfp & $7(17.8)$ & $1(2.6)$ \\
\hline
\end{tabular}

STEC - shigatoxigenic EHEC - enterohaemorrhagic, ETEC - enterotoxigenic, EPEC - enteropathogenic, EIEC - enteroinvasive, EAEC - enteroaggregative strains

Information on ERIC types, category, and nine antimicrobial resistance profiles of enterovirulent isolates are given in Table 3. All isolates tested by ERIC PCR had amplicons ranging from approximately 150 to $1500 \mathrm{bp}$. According to the dendogram (Plate I, Fig. 2), two groups with $30 \%$ genetic proximity were determined. Among 39 strains tested, a total of 28 types were detected. Twenty strains had distinct types while 5 types were common for 2 strains and 3 types were common for 3 strains. Clonal spread of a common strain was not detected among the animals tested in the present study.

\section{Discussion}

E. coli is an important bacterial agent of neonatal diarrhoea that causes great economic losses in the farming industry. E. coli has been reported as the causative agent of diarrhoea 
Table 3. Enterobacterial repetitive intergenic consensus types, category, and antibiotic resistance profiles of enterovirulent Escherichia coli isolated from lamb and goat kids with diarrhoea.

\begin{tabular}{|c|c|c|c|}
\hline $\begin{array}{l}\text { Number } \\
\text { of isolates }\end{array}$ & $\begin{array}{l}\text { ERIC } \\
\text { type }\end{array}$ & Category & Antibiotic resistance profile \\
\hline 1 & 1 & STEC & TET \\
\hline 2 & 6 & STEC & - \\
\hline 3 & 8 & STEC & TET \\
\hline 4 & 7 & STEC & - \\
\hline 5 & 10 & STEC & TET \\
\hline 6 & 12 & ETEC & - \\
\hline 7 & 14 & STEC & - \\
\hline 8 & 3 & EHEC & TET, PIP, SXT, AMP \\
\hline 9 & 20 & EHEC & TET \\
\hline 10 & 14 & STEC & - \\
\hline 11 & 11 & EHEC & - \\
\hline 12 & 4 & STEC & TET, PIP, SXT, AMP, GEN \\
\hline 13 & 17 & EPEC & - \\
\hline 14 & 21 & STEC & - \\
\hline 15 & 21 & STEC & - \\
\hline 16 & 22 & STEC & - \\
\hline 17 & 5 & EPEC & TET, PIP, SXT \\
\hline 18 & 17 & EPEC & - \\
\hline 19 & 17 & EPEC & - \\
\hline 20 & 15 & STEC & TET, PIP, SXT, AMP, CHL \\
\hline 21 & 2 & ETEC & TET, PIP, SXT, AMP, GEN, AMC, CEFP, CFT, TO, ENR, MAR ESBL + \\
\hline 22 & 13 & ETEC & - \\
\hline 23 & 2 & ETEC & TET, PIP, SXT, AMP, GEN, AMC, CEFP, CFT, TO, ENR, MAR ESBL + \\
\hline 24 & 24 & ETEC & TET \\
\hline 25 & 18 & ETEC & TET \\
\hline 26 & 19 & ETEC & TET \\
\hline 27 & 25 & ETEC & - \\
\hline 28 & 16 & ETEC & TET, SXT, CHL, ENR, MAR \\
\hline 29 & 23 & ETEC & - \\
\hline 30 & 9 & EHEC & TET, SXT, AMP \\
\hline 31 & 9 & STEC & TET, SXT, AMP \\
\hline 32 & 23 & ETEC & - \\
\hline 33 & 23 & ETEC & - \\
\hline 34 & 26 & EPEC & - \\
\hline 35 & 26 & EPEC & - \\
\hline 36 & 26 & EPEC & - \\
\hline 37 & 27 & STEC & - \\
\hline 38 & 27 & STEC & - \\
\hline 39 & 28 & EPEC & PIP, AMP, AMC, CEFP ESBL + \\
\hline
\end{tabular}

AMC - amoxicillin clavulanic acid, AMP - ampicillin, CEFP - cefpodoxime, CFT - ceftiofur, CHL - chloramphenicol, ENR - enrofloxacin, GEN - gentamicin, MAR - marbofloxacine PIP - piperacillin, SXT - trimethoprim sulfamethoxazole, TET - tetracycyline, TO - tobramicin, ESBL - extended spectrum beta lactamase, enterobacterial repetitive intergenic consensus ERIC, EHEC - enterohaemorrhagic, STEC - shigatoxigenic 
in small ruminants from Turkey (Gokce et al. 2010) and other states (Wani et al. 2004), however, research on classification of enterovirulent $E$. coli and its virulence genes is limited. Recent studies have reported (Wani et al. 2003; Bhat et al. 2008; Bandyopadhyay et al. 2011), the existence of at least one virulence gene in $41 \%, 36.7 \%$, and $32.6 \%$ of E. coli isolates, respectively. In our study we found at least one virulence gene for EHEC or STEC, EPEC, ETEC, EIEC, and EAEC among $36.4 \%$ of the isolates.

The prevalence of STEC in our study was $17.8 \%$ of $107 \mathrm{E}$. coli isolates tested. This rate was higher than the findings reported by Wani et al. (2003) from India (6\%), and was the same (17.8\%) to the findings of Bhat et al. (2008). However, the latest report from India showed that the STEC rate has increased to $32 \%$ (Bandyopadhyay et al. 2011). This may be an indication that if necessary precautions are not taken, pathogenic E. coli ratio may increase also in our country. In our study, the stx2 gene was more prevalent than the $s t x 1$ gene. This result contrasts with reports which showed that STEC strains isolated from small ruminants harbour the $s t x 1$ gene more frequently (Bhat et al. 2008; Wani et al. 2009) but agrees with Bandyopadhyay et al. (2011), who also found a predominance of the $s t x 2$ gene in STEC strains isolated from small ruminant with diarrhoea in India. Jenkins et al. (2002) reported that among healthy cattle, prevalence of VTEC strains may vary depending on the season. They found that except for winter, $s t x 2$ rates were higher among cattle. This is significant because $s t \times 2$ is a more important toxin for humans as the cause of the haemolytic uremic syndrome (Nataro and Kaper 1998).

Among newborn small ruminants, ETEC strains are the most important pathogen that causes diarrhoea. In our study, about $11.2 \%$ of 107 E. coli strains isolated from faeces of diarrhoeic lambs were harbouring specific gene(s) for ETEC. The latest study from India showed that $9 \%$ of the faecal isolates from lambs were ETEC. In India, among 22 ETEC positive isolates, five (23\%) possessed $l t$ genes, and another five possessed $s t$ genes (Bandyopadhyay et al. 2011). In our study, recovery of $l t$ was in high frequency (28.2\%) but $s t$ was in low frequency (2.6\%). The differences between the ratio of $s t$ and $l t$ in these studies may be due to geographical locations.

Diarrhoea associated with $E$. coli infections is often treated with antibiotics; however, therapy may be unsuccessful due to resistant strains in animals (Cid et al. 1996; Kolar et al. 2008). In our study, 10 (25.6\%) isolates were found to be multidrug resistant. The resistance level of Spanish isolates (Medina et al. 2011) was also high with $74.8 \%$ isolates resistant to at least 2 antimicrobials, $59.7 \%$ resistant to at least 4 antimicrobials, $34.9 \%$ resistant to at least 6 antimicrobials and $14 \%$ resistant to at least 8 antimicrobials. While tetracycline resistance rates were found to be $40.2 \%$ in our study, in previous studies (Blanco et al. 1996; Cid et al. 1996) the resistance was high $(>70 \%)$. High resistance rates to tetracycline may be due to extensive use of tetracycline in veterinary treatment.

In recent years, the dissemination of $E$. coli strains harbouring ESBL has caused great deal of concern. Although ESBL producing $E$. coli have been more clearly defined in the humans, they remain unclear in small ruminants. Hartmann et al. (2012) detected ESBL producing E. coli in livestock ( $5 \%$ of the animals tested) in France. In Europe, the isolation rates of such strains still remain low and have been only detected sporadically in cattle. Snow et al. (2011) detected ESBL producing E. coli on six farms in UK. To our best knowledge this is the first report of ESBL producing E. coli in lambs with diarrhoea in Turkey. Further epidemiological studies are necessary to investigate the status of the ESBL presence in the veterinary field.

The results of the present study showed that the isolation rates of STEC, ETEC, EPEC and EHEC strains were high. Although these isolates were not clonal, presence of multidrug resistant isolates may cause future public health problems. 


\section{Acknowledgement}

This work was supported by Republic of Turkey Food, Agriculture and Livestock, General Directorate of Agricultural Research and Policies (Project No: TAGEM/HS 10/08/02/164).

\section{References}

Bandyopadhyay S, Mahanti A, Samanta I, Dutta TK, Ghosh MK, Bera AK, Bandyopadhyay S, Bhattacharya D 2011: Virulence repertoire of shiga toxin-producing Escherichia coli (STEC) and enterotoxigenic Escherichia coli (ETEC) from diarrhoeic lambs of Arunachal Pradesh, India. Trop Anim Health Prod 43: 705-710

Beutin L, Steinruck H, Krause G, Steege K, Haby S, Hultsch G, Appel B 2007: Comparative evaluation of the Ridascreen Verotoxin enzyme immunoassay for detection of Shiga-toxin producing strains of Escherichia coli (STEC) from food and other sources. J Appl Microbiol 102: 630-639

Bhat MA, Nishikaw Y, Wani SA 2008: Prevalence and virulence gene profiles of Shiga toxin-producing Escherichia coli and enteropathogenic Escherichia coli from diarrhoeic and healthy lambs in India. Small Rumin Res 75: 65-70

Blanco J, Cid F, Blanco JE, Blanco M, Ruiz Santa Quitera JA, de Lafunte R1996: Serogroups, toxins and antibiotic resistance of Escherichia coli strains isolated from diarrhoeic lambs in Spain. Vet Microbiol 49: 209-217

Cid D, Piriz S, Santa Quitera JR, Valle J, Vadillo S, de Lafunte R 1996: In vitro susceptibility of Escherichia coli strains isolated from diarrhoeic lambs and goat kids to 14 antimicrobial agents. J Vet Pharmacol Ther 19: 397-401

Clinical and Laboratory Standards Institute (CLSI), 2007. Performance standards for antimicrobial susceptibility testing. Seventeenth informational supplement. M100-S17. Wayne, PA

Gokce E, Unver A, Erdogan HM 2010: Enteric pathogens in the aetiology of diarrhoea in neonatal lambs. Kafkas Univ Vet Fak Derg 16: 717-722

Hartman A, Locatellia A, Amoureux L, Deppret G, Jolivet C, Gueneau E, Neuwirth C 2012: Occurrence of CTX-M producing Escherichia coli in soils, cattle, and farm environment in France (Burgundyregion). Front Microbiol doi: 10.3389/fmicb.2012.00083

Jenkins C, Pearce MC, Chart H, Cheasty T, Willshaw GA, Guinn GJ, Dougan G, Smit HR 2002: An eightmonth study of a population of verocytotoxigenic Escherichia coli (VTEC) in a Scottish cattle herd. J Appl Microbiol 93: 944-953

Kolar M, Bardon J, Vagnerova I, Sauer P, Koukalova D, Petrzelova J, Cekanova L, Pospisil R 2008: Resistance to antibiotics in strains of Staphylococcus spp., Enterococcus spp. and Escherichia coli isolated from rectal swabs of pigs. Acta Vet Brno 77: 103-110

Ling TK, Tam PC, Liu ZK, Cheng AF 2001. Evaluation of Vitek II rapid identification and susceptibility testing system against Gram negative clinical isolates. J Clin Microbiol 39: 2964-2966

Lopez-Saucedo C, Cerna JF, Villergas-Sepulveda N, Thompson R, Velazquez FR, Torres J, Tarr PI, EstradaGarcia T 2003: Single multiplex polymerase chain reaction to detect diverse loci associated with diarrheagenic Escherichia coli. Emerg Infect Dis 9: 127-131

Medina A, Horcajo P, Jurado S, De La Fuente R, Ruiz-Santa-Quiteria JA, Dominguez-Bernal G, Orden JA 2011. Phenotypic and genotypic characterization of antimicrobial resistance in enterohemorrhagic Escherichia coli and atypical enteropathogenic E. coli strains from ruminants. J Vet Diagn Invest 23: 91-95

Nataro JP, Kaper JB 1998: Diarrheagenic Escherichia coli. Clin Microbiol Rev 11: 142-201

Quinn PJ, Carter ME, Markey BK, Carter GR 1994: Clinical Veterinary Microbiology. Mosby-Year Book Europe Limited, Lynton House, London WC1H9LB, England. pp. 209-236

Snow LC, Wearing H, Stephenson B, Teale CJ, Coldham NG 2011: Investigation of the presence of ESBL producing Escherichia coli in the north wales and west midlands areas of the UK in 2007 to 2008 using scanning surveillance. Vet Rec 169: 656 doi:10.1136/vr.100037

Versalovic J, Koeuth T, Lupski JR 1991: Distribution of repetitive DNA sequences in eubacteria and application to fingerprinting of bacterial genomes. Nucl Acids Res 19: 6823-6831

Vidal M, Kruger E, Duran C, Lagos R, Levine M, Prado V, Toro C, Vidal R 2005: Single multiplex PCR assay to identify simultaneously the six categories of diarrheagenic Escherichia coli associated with enteric infections. J Clin Microbiol 43: 5362-5365

Wani SA, Bhat MA, Samanta I, Ishaq SM, Ashrafi MA, Buchh AS 2004: Epidemiology of diarrhea caused by rotavirus and Escherichia coli in lambs in Kashmir valley, India. Small Rumin Res 52: 145-153

Wani SA, Bhat MA, Samanta I, Nishikawa Y, Buchh AS 2003: Isolation and charecterization of shiga toxinproducing Escherichia coli (STEC) and enteropathogenic Escherichia coli (EPEC) from calves and lambs with diarrhea in India. Lett Appl Microbiol 37: 121-126

Wani SA, Hussain I, Fayaz I, Mir MA, Nishikawa Y 2009: Subtype analysis of stx1, stx2 and eae genes in shiga toxin-producing Escherichia coli (STEC) and typical and atypical enteropathogenic E. coli (EPEC) from lambs in India. Vet J 182: 489-490 
Plate I

Turkyilmaz S. et al.: Identification... pp. 357-362

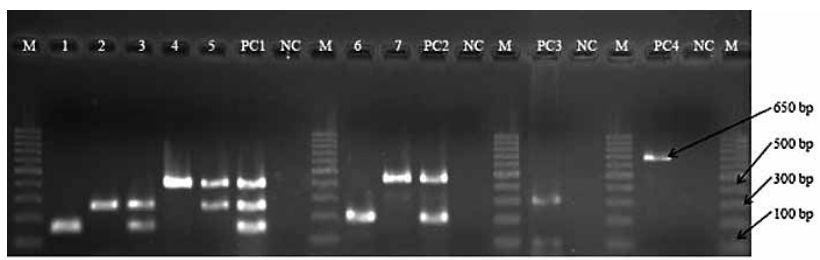

Fig. 1. Multiplex and uniplex PCR profiles detected among 39 isolates of $E$. coli with virulence gene.

1 - stx 1 positive ( 1 strain; $150 \mathrm{bp}$ ), 2 - stx 2 positive (13 strains; $255 \mathrm{bp}$ ), 3 - stx 1 and stx 2 positive ( 1 strain; $150 \mathrm{bp}, 255 \mathrm{bp}$ ), 4 - eaeA positive (7 strains; $384 \mathrm{bp)} 5$ - st 2 and eaeA positive ( 4 strains; $255 \mathrm{bp}, 384 \mathrm{bp}$ ) 6 - st positive (1 strain; $190 \mathrm{bp}$ ) 7 - lt positive (11 strains; $450 \mathrm{bp}$ ), M - Marker (100 bp DNA ladder) NC - negative control (ATCC 25922) PC - positive control, PC1 - EHEC (ATCC 35150; 150 bp, 255 bp and $384 \mathrm{bp}$ ), PC2 - ETEC (ATCC 35401; $190 \mathrm{bp}$ and $450 \mathrm{bp}$ ), PC3 - bfp positive field isolate (1 strain; $300 \mathrm{bp}$ ), PC4 - EIEC (ATCC 43893; 650 bp)

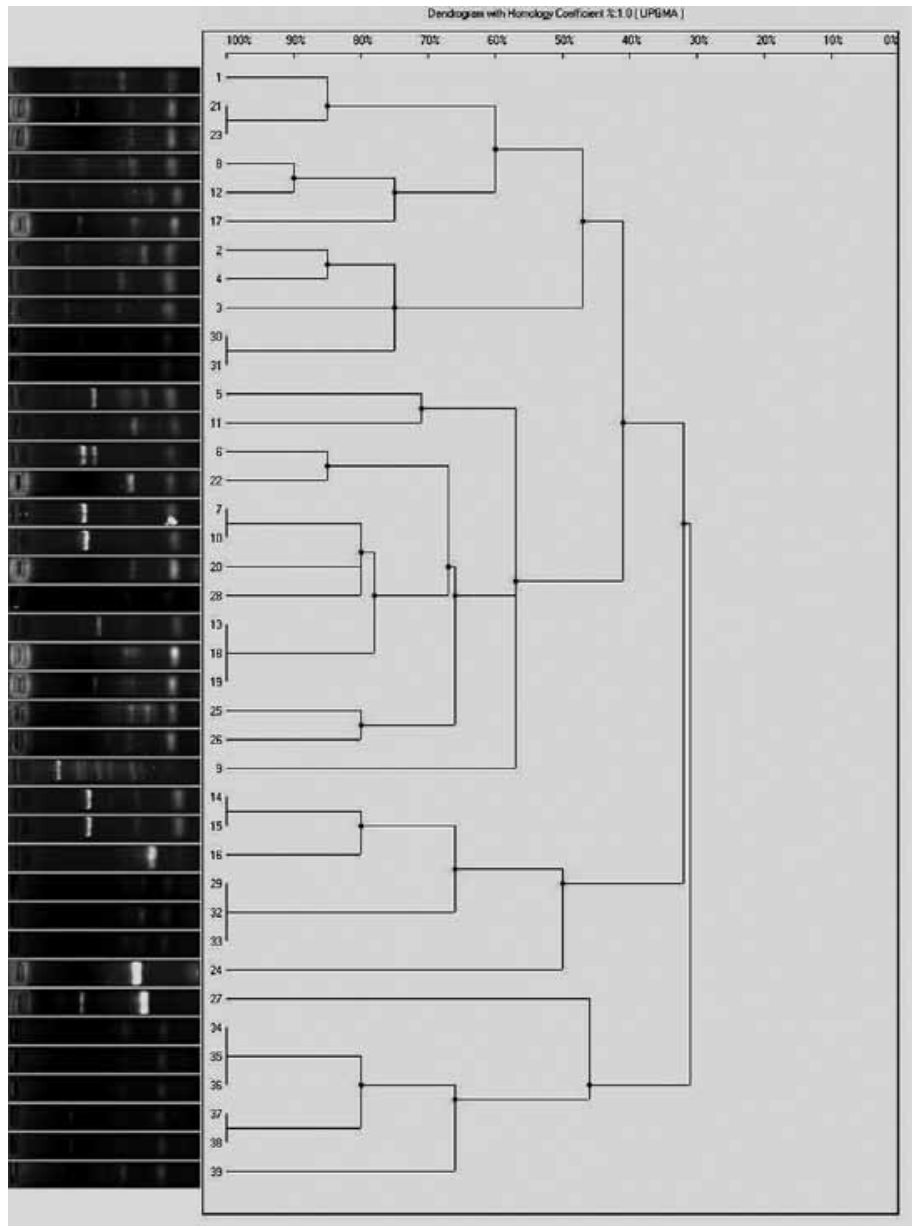

Fig. 2. Dendogram of enterovirulent $E$. coli strains isolated from lamb and goat kids with diarrhoea. Results from ERIC PCR showed presence of 28 types among 39 isolates tested. Although these isolates were not clonal, twenty strains had distinct types while 5 types were common for 2 strains and 3 types were common for 3 strains 